\title{
Neuroimaging outcomes for writing epilepsy with generalized tonic clonic seizure: a case description and literature analysis
}

\author{
Baodong Li ${ }^{1 \#}$, Meimei Jin ${ }^{1 \#}$, Jing Bai ${ }^{2}$, Guobin Lan $^{1}$, Xiaowei Qiu ${ }^{1}$ Jia Song ${ }^{1}, Z_{\text {Zhenfeng Sun }}{ }^{1}$, Yong Liu ${ }^{1}$, \\ Zengyue $\mathrm{Zhu}^{1}$ \\ ${ }^{1}$ Department of Neurology, Cangzhou Hospital of Integrated Traditional Chinese and Western Medicine, Cangzhou, China; ${ }^{2}$ Department of \\ Neurology, Dongzhimen Hospital, Beijing University of Traditional Chinese Medicine, Beijing, China \\ "These authors contributed equally to this work.
}

Correspondence to: Baodong Li. Department of Neurology, Cangzhou Hospital of Integrated Traditional Chinese and Western Medicine, Cangzhou, China. Email: lbd_doctor@163.com; Jing Bai. Department of Neurology, Dongzhimen Hospital, Beijing University of Traditional Chinese Medicine, Beijing, China. Email: baijingdoctor@163.com.

Submitted May 17, 2021. Accepted for publication Oct 27, 2021.

doi: 10.21037/qims-21-533

View this article at: https://dx.doi.org/10.21037/qims-21-533

\section{Introduction}

Writing-induced seizures have been documented and described since the past few decades (1-3). Writing epilepsy includes combination of various myoclonic jerks of ipsilateral or bilateral hand induced by writing, sometimes accompanied by local dystonic posture of hand, which can rapidly develop into generalized tonic-clonic seizure (GTCS) (4). The International League Against Epilepsy (ILAE) have classified the GTCS with partial onset and secondary generalization in to focal-to-bilateral tonicclonic seizure in 2017 (5). Seizure-precipitating factors are closely related to brain activities $(6,7)$ and have varying influence on the diverse epilepsies due to their underlying pathophysiological characteristics. Rarely, published literature have specified the role of brain cortex in inducing seizures due to writing $(1,8,9)$. Herein, we report a very rare case of epilepsy elicited exclusively by writing. The major factors triggering the seizures associated with the writing process were investigated via electroencephalogram (EEG) and magnetic resonance imaging/positron emission tomography fusion imaging (MRI/PET).

\section{Case presentation}

A 34-year-old right-handed man has been attending at our institution with an episode of myoclonic jerks in his right hand since he was 31 years old. The patient first showed symptoms of right-hand jerks while writing Chinese sentences (native language) as a 21-year-old, followed by focal to bilateral tonic-clonic seizure that recovered completely in about $2-3 \mathrm{~min}$. The patient had no family history of epilepsy. At the age of 19, he suffered from a mild head injury, and experienced no other injury except for scalp abrasion. During the next 10 years as a $21-31$-year-old, there were 5 similar episodes, all of which were precipitated while writing Chinese sentences with his right hand, especially under psychological stress. At the time of attack, the patient experienced sudden jerks in his right arm, difficulty in holding the pen, and sometimes head discomfort. This ictal behavior ceased when the writing action was stopped immediately and completely relieved in a few seconds, however, it was accompanied by a mild sweating and palpitation, paresthesia with a latency of about $3 \mathrm{~min}$. While, if he continued to write, he eventually developed focal to bilateral tonic-clonic seizure. A proper diagnosis and standardized treatment was not established for the patient.

At the time of his first visit as a 31-year-old, his neurological and physical examinations were normal. Computed tomography (CT) and MRI showed no abnormality. The 24-h video EEG (VEEG) monitoring during neuropsychological tests (NPT) showed normal 


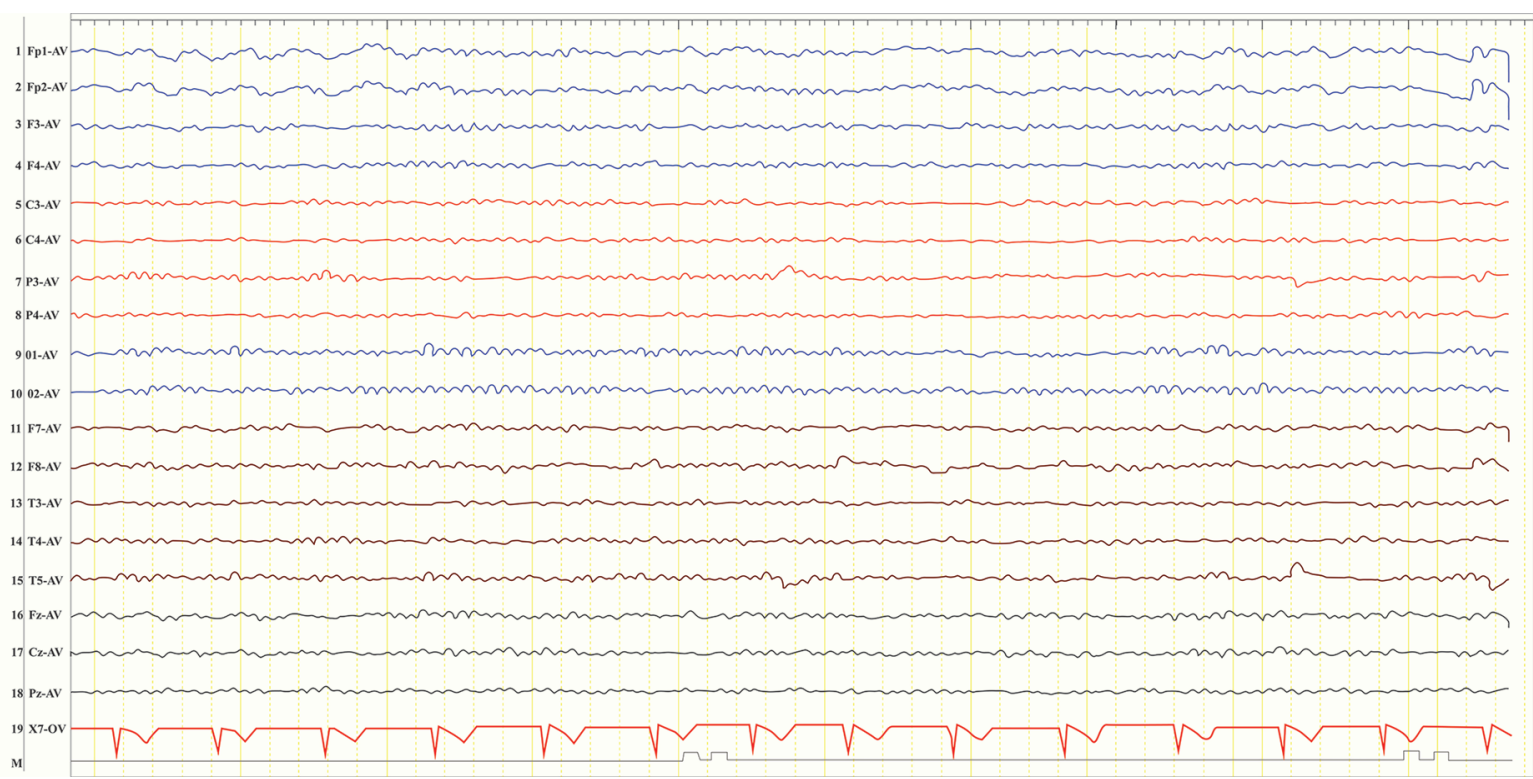

Figure 1 Normal background cerebral activity via 24-h VEEG monitoring. VEEG, video electroencephalogram.

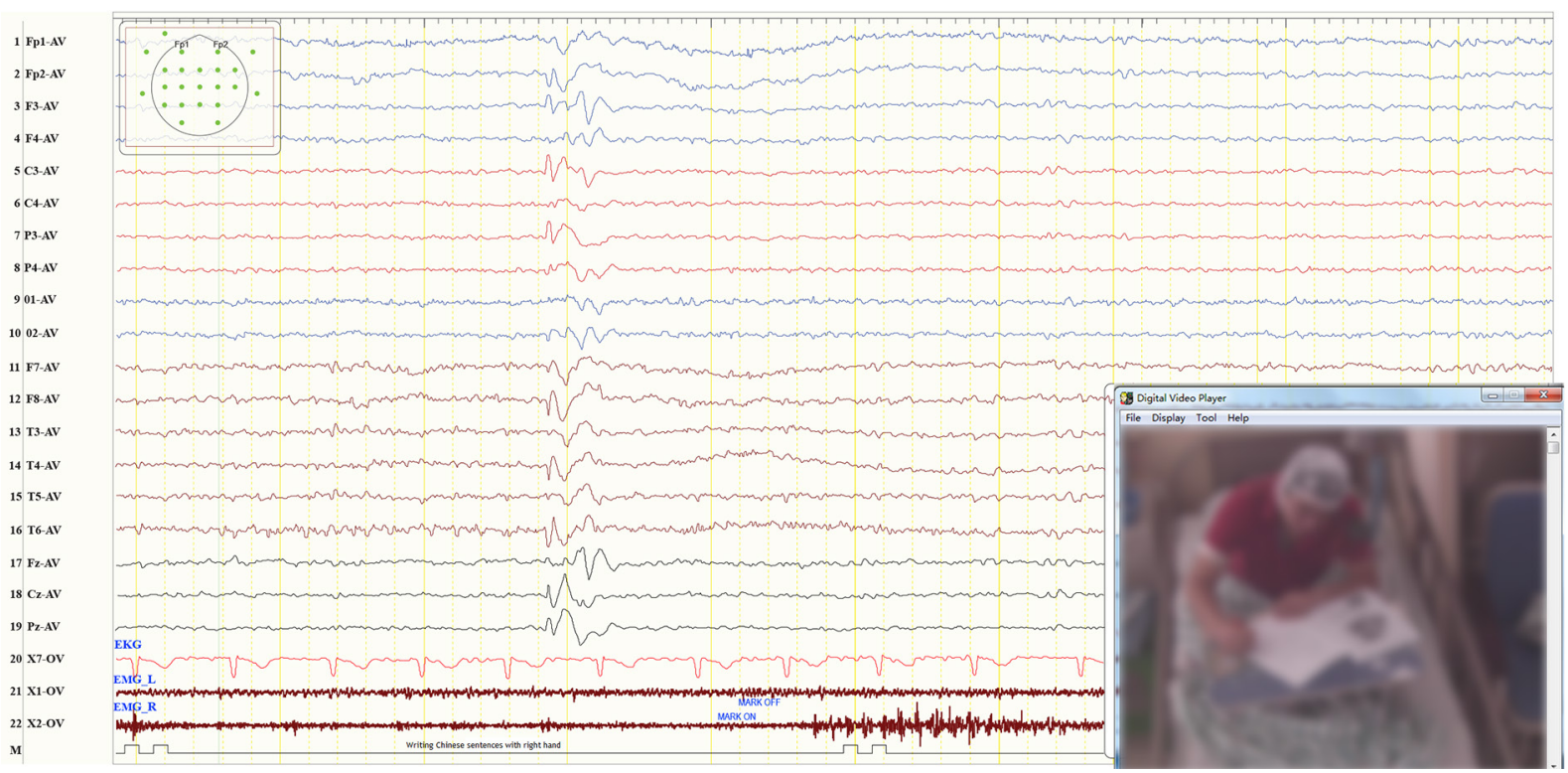

Figure 2 Asymmetrical epileptiform discharges when patient was writing Chinese sentences with the right hand for $90 \mathrm{~s}$. This image is published with the patient's consent.

background cerebral activity (Figure 1). When writing Chinese sentences with his right hand for $90 \mathrm{~s}$, VEEG showed a small amount of medium amplitude spikes and slow waves in the left frontal, central and parietal lobe as well as central and parietal midline areas (Figure 2). While writing after a latent period of $10 \mathrm{~min}$, the discharge did not increase significantly, nor did it induce convulsions. On cessation of writing activity, the discharge decreased and disappeared completely after about $3 \mathrm{~s}$. No clinical symptoms or EEG discharges were induced by other NPTs 
Table 1 Neuropsychological tests

\begin{tabular}{lcc}
\hline Task & $\begin{array}{c}\text { Clinical } \\
\text { symptoms }\end{array}$ & $\begin{array}{c}\text { Epileptiform discharge } \\
\text { (evoked time in seconds) }\end{array}$ \\
\hline Read & - & - \\
Chinese & - & - \\
English & - & - \\
Retell & - & - \\
Chinese & & - \\
English & - & - \\
Name & - & - \\
Chinese & & - \\
English & - & - \\
Listening comprehension & & - \\
Chinese & - & \\
English & - & \\
Spontaneous conversation & & \\
Chinese & - & \\
English & & \\
\hline
\end{tabular}

-, negative induction (EEG changes without clinical symptoms). EEG, electroencephalogram.

such as reading, retelling, translation, naming and other language functions.

We conducted more NPTs where the patient was asked to perform several tasks. The time of evoked response for each task was set at 180 s. If EEG abnormality occurred before $180 \mathrm{~s}$, the task was terminated ahead of time. These results are summarized in Tables 1,2. Spontaneous writing, dictation, transcription, thought of writing, subtraction and multiplication calculation, writing simple as well as complex sentences elicited clinical symptoms and epileptiform discharges (+, induction), while, holding objects, finger tapping, reading, retelling, naming, listening comprehension, spontaneous conversation did not elicit epileptiform discharges (-, induction).

The patient experienced clinical symptoms such as head discomfort [identified as a consequence of myoclonus jerks by electromyography (EMG) monitoring], confusion, jerks on the right arm while holding the pen, which gradually became uncontrollable (in contrast, there was sense of control in both hands when he wrote by the left hand). Sometimes, when the epileptiform discharges continued, the patient went into a trance while writing and would lose
Table 2 Neuropsychological tests

\begin{tabular}{|c|c|c|c|c|}
\hline \multirow{2}{*}{ Task } & \multicolumn{2}{|c|}{ Clinical symptoms } & \multicolumn{2}{|c|}{$\begin{array}{l}\text { Epileptiform discharge } \\
\text { (evoked time in seconds) }\end{array}$} \\
\hline & Left hand & Right hand & Left hand & Right hand \\
\hline \multicolumn{5}{|l|}{ Calculations } \\
\hline Addition & $\mathrm{N}$ & - & $\mathrm{N}$ & - \\
\hline Subtraction & $\mathrm{N}$ & + & $\mathrm{N}$ & $+(13 s)$ \\
\hline Multiplication & $\mathrm{N}$ & + & $\mathrm{N}$ & $+(22 \mathrm{~s})$ \\
\hline Division & $\mathrm{N}$ & - & $\mathrm{N}$ & - \\
\hline \multicolumn{5}{|c|}{ Spontaneous writing } \\
\hline Chinese & + & + & $+(78 \mathrm{~s})$ & $+(39 \mathrm{~s})$ \\
\hline English & - & + & - & $+(46 \mathrm{~s})$ \\
\hline Graphical & - & - & - & - \\
\hline Drawing & - & - & - & - \\
\hline \multicolumn{5}{|l|}{ Transcription } \\
\hline Chinese & - & + & - & $+(149 \mathrm{~s})$ \\
\hline English & & + & - & $+(123 \mathrm{~s})$ \\
\hline Graphical & - & - & - & - \\
\hline Drawing & - & - & - & - \\
\hline \multicolumn{5}{|l|}{ Dictation } \\
\hline Chinese & - & - & $+(160 \mathrm{~s})$ & $+(52 \mathrm{~s})$ \\
\hline English & - & - & - & - \\
\hline Graphical & - & - & - & - \\
\hline Drawing & - & - & - & - \\
\hline \multicolumn{5}{|l|}{ Thinking of writing } \\
\hline Chinese & - & - & - & $+(25 \mathrm{~s})$ \\
\hline English & - & - & - & - \\
\hline Graphical & - & - & - & - \\
\hline Drawing & - & - & - & - \\
\hline Possession & - & - & - & - \\
\hline Finger tapping & - & - & - & - \\
\hline
\end{tabular}

consciousness which was presented as an episode of seizure with EEG ictal changes. The epileptiform discharges were discontinued at this stage to prevent extension of focal seizure to bilateral tonic-clonic seizures. The epileptiform discharges were almost similar in the left frontal, central 


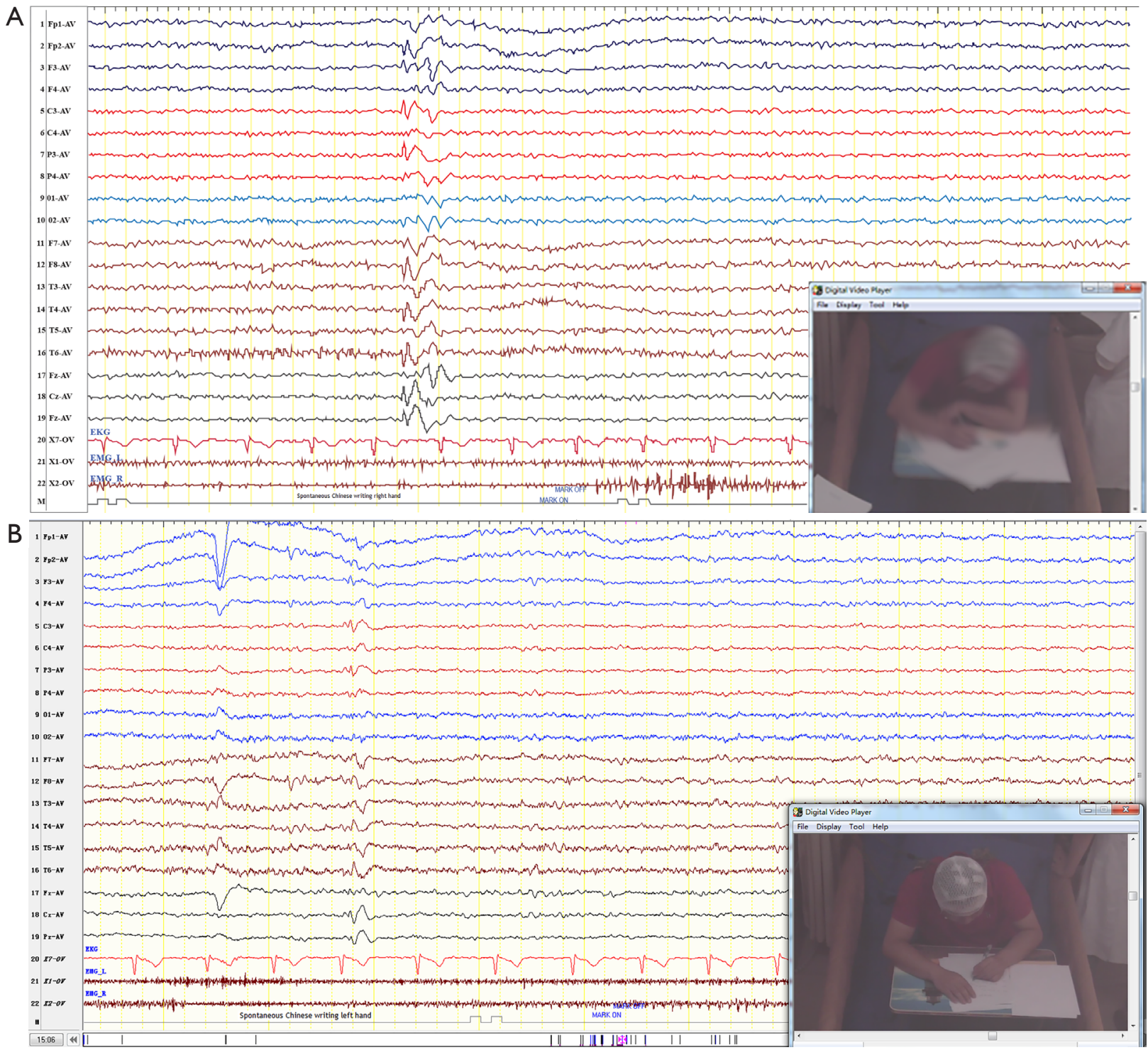

Figure 3 Epileptiform discharges when patient performed spontaneous Chinese writing (A) right hand (B) left hand. These images are published with the patient's consent.

and parietal lobes as well as central and parietal midline regions, with the tendency to spread to the corresponding contralateral brain regions (Figure 3). The hand jerks were time-locked to epileptiform discharges and no epileptiform discharge was recorded during the intermittent period. We observed a relationship between clinical symptoms and epileptiform discharge: (I) when both abnormalities were elicited, they appeared almost at the same time. With epileptiform discharge the patient would complain of head discomfort, while performing subtraction and multiplication by right hand, spontaneous writing of Chinese with left hand, spontaneous writing of Chinese and English with right hand, and transcription of Chinese and English with right hand; (II) when epileptiform discharges were elicited alone, the patient did not experience any clinical symptoms, however showed epileptiform discharges in left hemisphere only in tasks of spontaneous Chinese dictation with left hand, spontaneous Chinese dictation with right hand, and thinking of writing in Chinese with right hand; (III) no events of paresthesia without EEG abnormalities were recorded. Clinical symptoms and epileptiform discharges were elicited when writing with both the hands, but the 

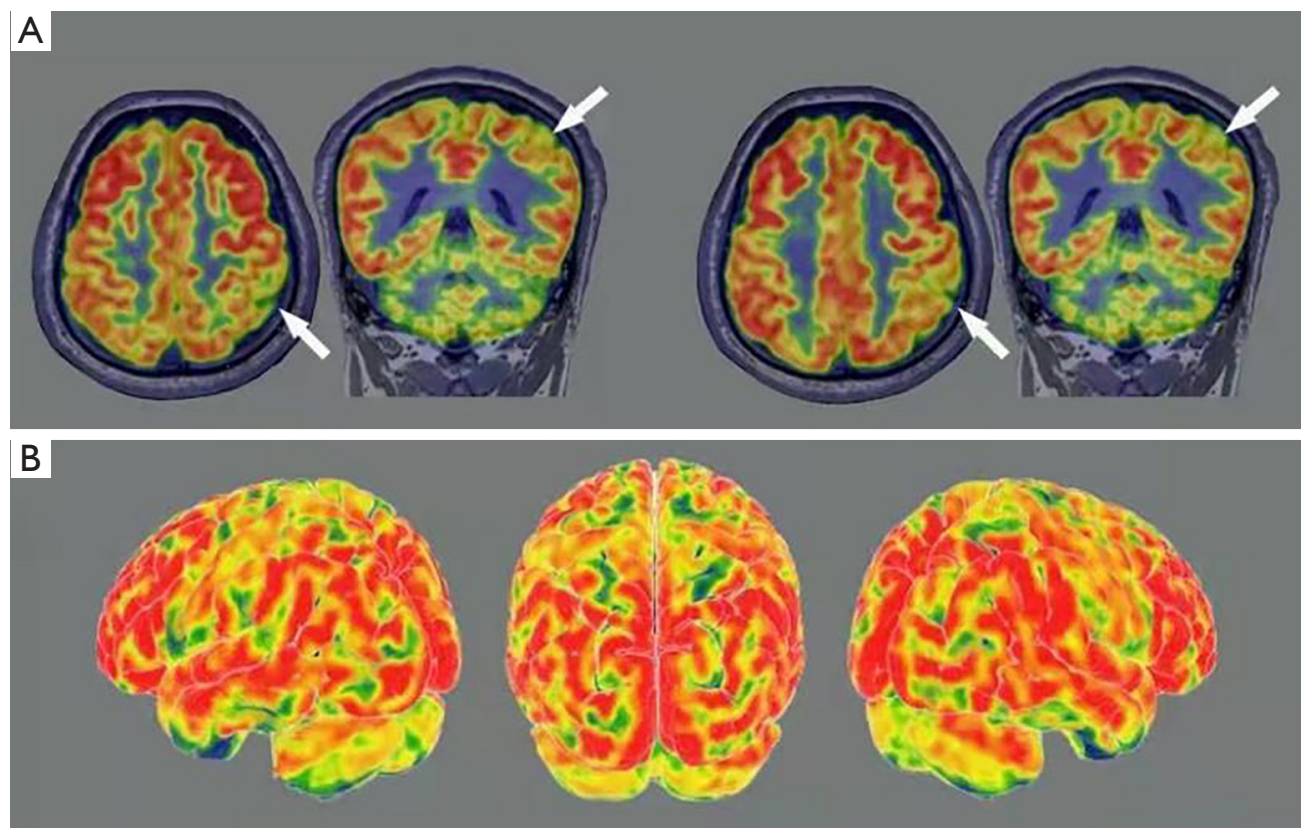

Figure 4 PET-MRI fusion revealed hypometabolism of left parietal lobe. Hypometabolism area of left parietal lobe (white arrow). PET, positron emission tomography; MRI, magnetic resonance imaging.

changes were more prominent when writing by the right hand compared to writing by the left hand (left/right $=3 / 14$ ). In addition, the duration of inducing epileptic activity with the right hand was shorter than the left hand. For example, the time to induce epileptic seizure with right-hand English writing was only $3 \mathrm{~s}$.

Structural MRI (3.0 T) was performed with no interval scanning at thickness of $1 \mathrm{~mm}$ covering coronal, axial and sagittal planes and showed no abnormality. PET showed moderately decreased glucose metabolism in left parietal lobe, while PET-MRI fusion imaging revealed a hypometabolism of left parietal lobe (Figure 4).

All procedures performed in studies involving human participants were in accordance with the ethical standards of the institutional and/or national research committee(s) and with the Helsinki Declaration (as revised in 2013). Written informed consent was obtained from the patient for publication of this case report and accompanying images. A copy of the written consent is available for review by the editorial office of this journal.

The patient was given levetiracetam $0.5 \mathrm{~g}$, once in the morning and evening. After 3 months of follow-up, the symptoms of the patient improved, and writing did not induce myoclonic jerks and convulsions. After 3 years, he stopped consuming levetiracetam completely and did not experience any epileptic seizures on short-term writing. However, he gradually developed anxiety and stopped writing for a long time, which hampered his professional and personal life.

\section{Discussion}

Writing epilepsy is a kind of reflex epilepsy with an onset age between 18-35 years. Published literatures reveal writing to be a predisposing factor for this kind of epileptic seizure $(4,9,10)$. In our case, the patient exhibited writing-induced seizures, with the dominant right-hand inducing major clinical symptoms and/or epileptiform discharges, while performing tasks such as spontaneous writing of Chinese and English sentences, transcription of Chinese and English sentences, dictation of Chinese, and thought of writing in Chinese. Whilst, writing with left hand led to induction of only spontaneous writing and dictation of Chinese. This suggest that writing by both right and left hands was responsible for induction of epileptiform activity. We noted that the epileptiform discharges induced by both hands were almost similar. At the same time, the epileptiform discharges originated from the dominant left hemisphere and tend to spread to the corresponding contralateral brain regions. Thus, no matter whichever hand the patient 
used for writing, the epileptiform discharges were elicited in the left hemisphere only. Similarly, in a case report by Jabeen et al. (11), a 24-year-old right-handed individual experienced epileptiform activity while writing with either hand, but prominently with right hand. However, in a case report by Ohima et al. (4), writing with the left hand was not associated with any EEG changes and no distinguished clinical symptoms were observed while writing with left hand. In a case series, an interesting observation was made during neuropsychological EEG activation where mental activity performed with the hands provoked the centraldominant discharges with unilateral myoclonic seizure as well as generalized discharges with bilateral myoclonic seizure suggesting that thinking of writing can also produce electrical discharges leading to seizures (12). Similar pattern was seen in a study by Tanaka et al. (13) where seizures triggered by writing as well as thinking of writing showed the same electroclinical features in 2 patients with graphogenic epilepsy. However, conclusion cannot be drawn on the association of thinking of writing with development of seizures in patients with writing epilepsy, as two sisters with juvenile myoclonic epilepsy in whom writing activity triggered epileptic myoclonic jerks of both arms and hands did not elicit seizures or myoclonus while thinking of writing in both the patients (9).

Several studies suggest that the underlying mechanism of writing epilepsy may generate presumably from the left frontal lobe $(4,10)$, but an abnormality in the parietal lobe, observed on functional imaging may play an important role in reducing the threshold of epileptiform discharges. For instance, a study by Racicot et al. (14) reported that their patient experienced reflex seizures which was precipitated mainly due to writing and focal cortical dysplasia in the inferior parietal lobe. The focal cortical dysplasia in this patient was correlated with hypometabolism. Similar to this case, in our study, PET fusion imaging revealed hypometabolism in the parietal lobe and could be another reason for the induction of seizures. A magnetic resonance spectroscopy (MRS) might give a better information on type of metabolites and facilitate the diagnosis of epilepsy (15). A review article by Pan $e$ al. (16) also suggested the use of MRS imaging for human epilepsy and seizure localization with 4T, 7T and most recently $3 \mathrm{~T}$. In this patient, structural MRI (3.0 T) was performed which showed absence of any abnormalities.

EEG revealed ictal abnormalities associated with writing such as spontaneous writing, dictation, transcription, thought of writing, subtraction and multiplication calculation, while no abnormality was induced on holding objects, finger tapping, reading, retelling, naming, listening comprehension and spontaneous conversation. Thus, writing must have been a very powerful trigger for initiating cascade of brain reactions, leading to pure writing seizures. This also outlines that hand movements associated with the writing process might be a major factor in the seizure mechanism. Furthermore, it was observed that most of the ictal abnormalities were induced when the patient wrote in Chinese rather than English, suggesting that ease of native language is more likely to ignite the abnormal brain network of reflex epilepsy.

Previous literature indicate that the possible causes of reflex writing epilepsy include focal cortical dysplasia (14) inherit traits of seizures (9) and prior history of epilepsy $(9,10,14,17)$. Usually, myoclonic seizures of one or both hands are precipitated by writing, which can rapidly develop into systemic myoclonus or focal to bilateral tonic-clonic seizure $(9,10)$. If there is no focal to bilateral tonic-clonic seizure during the attack, the patients generally do not have impaired consciousness. Our patient repeatedly expressed head discomfort and loss of control of holding pen, and was identified as a consequence of myoclonus jerks, which was also verified by EMG monitoring during the same period. In our patient, since the epileptiform discharges were discontinued for fear of developing focal to bilateral tonicclonic seizure followed by myoclonus seizures, the patient didn't lose consciousness. In addition, we observed that termination of writing activity caused the clinical symptoms and epileptiform discharges to disappear.

Few studies reported normal EEG scans in epilepsy patients $(9,10)$, while in another study, hexamethylenepropylene amine oxime single-photon emission computed tomography (HMPAO-SPECT) reported interictal hypoperfusion in the right parietofrontal area in their patient (10). In our patient, writing with right hand reproduced sharp waves in the left central and parietal areas, accompanied by clinical symptoms. It must be noted, though not all abnormal discharge sites of EEG are located in the contralateral brain area of the writing hand, abnormal discharge would be produced generally in the contralateral brain area of the myoclonic hand. Our observation show that "writing" is the key initiating factor of abnormal epileptiform discharges, and its activation in cerebral cortex does not completely follow the principle of cross domination. It is suggested that writing can stimulate certain functional subsystems especially hyperexcitation and abnormally coupled with other areas, 
which are necessary for the critical mass needed for seizure initiation. This significant network is often identified as a parietofrontotemporal network $(18,19)$, which includes the intraparietal sulcus, the inferior parietal lobule, the middle frontal gyrus, the superior parietal sulcus, the premotor cortex, and the inferior frontal cortex (19).

Treatment with valproic acid and in some cases surgery (14) controls seizure in most patients. In our case, the seizure of this patient was controlled after taking levetiracetam, indicating that writing epilepsy may be sensitive to a variety of antiepileptic drugs (AEDs).

In conclusion, this case is an example of pure writing epilepsy, confirmed by clinical semiology and EEG findings. Though the etiology is unknown, it is associated with a small amount of medium amplitude spikes and slow waves in the left frontal, central and parietal lobe as well as central and parietal midline areas and a relevant left hemisphere participation, as suggested by ictal EEG findings.

\section{Acknowledgments}

We would like to extend our gratitude to Professor Liankun Ren, an epilepsy expert from Hospital of Capital Medical University. Without his guidance, the data could not be collected so completely.

Funding: None.

\section{Footnote}

Conflicts of Interest: All authors have completed the ICMJE uniform disclosure form (available at https://dx.doi. org/10.21037/qims-21-533). The authors have no conflicts of interest to declare.

Ethical Statement: The authors are accountable for all aspects of the work in ensuring that questions related to the accuracy or integrity of any part of the work are appropriately investigated and resolved. All procedures performed in studies involving human participants were in accordance with the ethical standards of the institutional and/or national research committee(s) and with the Helsinki Declaration (as revised in 2013). Written informed consent was obtained from the patient for publication of this case report and accompanying images. A copy of the written consent is available for review by the editorial office of this journal.

Open Access Statement: This is an Open Access article distributed in accordance with the Creative Commons Attribution-NonCommercial-NoDerivs 4.0 International License (CC BY-NC-ND 4.0), which permits the noncommercial replication and distribution of the article with the strict proviso that no changes or edits are made and the original work is properly cited (including links to both the formal publication through the relevant DOI and the license). See: https://creativecommons.org/licenses/by-nc-nd/4.0/.

\section{References}

1. Geschwind N, Sherwin I. Language-induced epilepsy. Arch Neurol 1967;16:25-31.

2. Bennett DR, Mavor H, Jarcho LW. Language-induced epilepsy: report of a case. Electroencephalogr Clin Neurophysiol 1971;30:159.

3. Jacome DE. Language-apparent reflex epilepsy. Clin Electroencephalogr 1991;22:172-7.

4. Oshima T, Hirose K, Murakami H, Suzuki S, Kanemoto K. Graphogenic epilepsy: a variant of language-induced epilepsy distinguished from reading- and praxis-induced epilepsy. Seizure 2003;12:56-9.

5. Fisher RS, Cross JH, French JA, Higurashi N, Hirsch E, Jansen FE, Lagae L, Moshé SL, Peltola J, Roulet Perez E, Scheffer IE, Zuberi SM. Operational classification of seizure types by the International League Against Epilepsy: Position Paper of the ILAE Commission for Classification and Terminology. Epilepsia 2017;58:522-30.

6. Fenwick PB, Brown SW. Evoked and psychogenic epileptic seizures. I. Precipitation. Acta Neurol Scand 1989;80:535-40.

7. Brown SW, Fenwick PB. Evoked and psychogenic epileptic seizures: II. Inhibition. Acta Neurol Scand 1989;80:541-7.

8. Matsuoka H, Takahashi T, Sasaki M, Yoshida S, Numachi Y, Sato $M$. The long-term course of seizure susceptibility in two patients with juvenile myoclonic epilepsy. Seizure 2002;11:126-30.

9. Chifari R, Piazzini A, Turner K, Canger R, Canevini MP, Wolf P. Reflex writing seizures in two siblings with juvenile myoclonic epilepsy. Acta Neurol Scand 2004;109:232-5.

10. Abreu P, Ribeiro M, Forni A, Pires I, Sousa G. Writing epilepsy: a neurophysiological, neuropsychological and neuroimaging study. Epilepsy Behav 2005;6:463-6.

11. Jabeen SA, Chowdary AH, Mridula KR, Cherian A, Kumar PR, Sarva S, Murty CV. Pure graphogenic epilepsy - a rare form of reflex epilepsy. Can J Neurol Sci 2013;40:603-5.

12. Matsuoka H. Seizure generation mechanisms in reflex epilepsy. Jpn J Psychiatry Neurol 1990;44:317-20. 
13. Tanaka N, Sakurai K, Kamada K, Takeuchi F, Takeda Y, Koyama T. Neuromagnetic source localization of epileptiform activity in patients with graphogenic epilepsy. Epilepsia 2006;47:1963-7.

14. Racicot F, Obaid S, Bouthillier A, Guillon-Létourneau L, Clément JF, Nguyen DK. Praxis-induced reflex seizures mainly precipitated by writing due to a parietal focal cortical dysplasia. Epilepsy Behav Case Rep 2016;6:52-4.

15. Liu D, Yang Y, Chen D, Wang Z, Guo D, Bao L, Dong J, Wang X, Qu X. Brain metabolic differences between temporal lobe epileptic seizures and organic non-epileptic seizures in postictal phase: a retrospective study with magnetic resonance spectroscopy. Quant Imaging Med Surg 2021;11:3781-91.

Cite this article as: Li B, Jin M, Bai J, Lan G, Qiu X, Song J, Sun Z, Liu Y, Zhu Z. Neuroimaging outcomes for writing epilepsy with generalized tonic clonic seizure: a case description and literature analysis. Quant Imaging Med Surg 2022;12(3):21702177. doi: 10.21037 /qims-21-533
16. Pan JW, Kuzniecky RI. Utility of magnetic resonance spectroscopic imaging for human epilepsy. Quant Imaging Med Surg 2015;5:313-22.

17. Buklina SB, Pronin IN, Zhukov VY, Pilipenko YV, Maryashev SA. Rare cases of reflex epilepsy in patients with gliomas of the left hemisphere. Zh Vopr Neirokhir Im N N Burdenko 2014;78:49-56; discussion 56.

18. Haaland KY, Harrington DL, Knight RT. Neural representations of skilled movement. Brain 2000;123 (Pt 11):2306-13.

19. Króliczak G, Frey SH. A common network in the left cerebral hemisphere represents planning of tool use pantomimes and familiar intransitive gestures at the handindependent level. Cereb Cortex 2009;19:2396-410. 